\title{
EL LLIBRE D'AMIC I AMAT DE RAMON LLULL: MODESTA CONTRIBUCIÓN AL ESTUDIO DE SUS FUENTES
}

\author{
Vincent Serverat \\ Universidad Stendhal - Grenoble III (CERHIUS-SEHM)
}

\begin{abstract}
RESUMEN
Estudio intertextual del Llibre d'amic i amat en los ámbitos de la espiritualidad, de la teología y de la literatura vernacular, sobre todo mediante referencias a la patrística latina, el pensamiento de cistercienses y victorianos, la legenda de Ami et amile, etc. Se adopta el método de las filiaciones, pero con rectificaciones notables: no basta con señalar el parentesco de motivos y temas, etapa que debe prolongarse por un estudio de la función y el sentido de dichos elementos en la arquitectura, el sistema de un pensamiento. Se pone de realce, asimismo, la importancia de compaginar filosofía y poética, en torno a lo que pudiera ser una tipología del exemplum en el opúsculo luliano.
\end{abstract}

Palabras clave: Mística, Literatura catalana, Filosofía medieval, Lulismo, Esemplum.

\begin{abstract}
Intertextual study of the Libre d'amic $i$ amat in the fields of spirituality, theology and literature, with special references to the latin patristic, the thought of the Cistercians and the Victorines, the legenda of Ami et Amile, etc. The method of filiations and sources is adopted, but with major corrections: the likeliness about themes and motifs has not only to be pointed; that first step must be prolonged by an interrogation about the sense and the function of these elements in the architecture, the systeme of a particular thought. The a. emphatises also how relevant to unify philosophy and poetics it is; in that way, he outlines the chief features of one possible tipology for the examplum in the lullian opuscule.
\end{abstract}

Key words: Mystic, Catalan literature, Medieval Philosophy, Lullism, Exemplum.

En 1995 salía a la luz la edición crítica del Llibre d'amic $i$ amat (Laa) de Ramon Llull (c.1232c.1316), fruto de un esmerado trabajo de Albert Soler, en la serie B de Els nostres clàssics. ${ }^{1} \mathrm{De}$ acuerdo con las normas de dicha colección, el establecimiento del texto predomina sobre su comentario, lo que se traduce por la ausencia de anotaciones culturales y literarias, que completen el riquísimo aparato de variantes textuales que, en el caso que nos ocupa, se extiende a versiones en catalán, latín, francés y aprovenzalada. Junto con nuestra admiración por dicho trabajo ejemplar, no podemos menos que echar en falta un aparato de notas culturales, tanto más cuanto que lo permi-

1 Ramon Llull, Libre d'amic i amat, A. Soler (ed.), dans Els nostres clàssics B-13, Barcelona, Barcino, 1995, 310 p. 
tían las 310 páginas del volumen in quarto. Dicha tarea nos parecía imponerse tanto más cuanto que, en el plano textual, la presente edición crítica ya no podía representar, por razones obvias, una pequeña revolución, como lo fuera, en su tiempo, la versión de Galmés y Ferrà de 1914, la primera en suprimir las abundantes interpolaciones humanistas del texto. Por sus intereses exclusivamente -y repitámoslo, ejemplarmente- paleográficos, la nueva edición no ofrece tampoco una bibliografía exhaustiva sobre el $L a a$, lo cual, sin representar una ingente masa de estudios, hubiera aportado un valioso instrumental para uso del investigador. En resumidas cuentas, esta obra maestra, repetidas veces editada, sigue careciendo de un aparato de notas que pueda orientar al lector en el laberinto de sus contextos, tanto intrínseco (el arduo y evolutivo pensamiento luliano) como extrínseco (su inserción en el entorno de la época).

Con estas páginas, deseamos aportar nuestro granito de arena a la tarea de la elucidación de un texto enigmático, tanto por su extremada originalidad como por su carácter atípico, difícil de encajar, en el casillero de los géneros medievales. Lo que nos proponemos, con nuestro trabajo, es efectuar una pesquisa sobre su génesis, rastreando las posibles fuentes del autor. No se nos oculta que la problemática de las fuentes es secundaria, pues lo esencial, en el Laa como en toda obra señera, no radica tanto en el inventario de materiales como en el proyecto vital y literario que rige su composición. Una vez reconocidas sus limitaciones, partiremos una lanza por dicho método, el cual nos sigue pareciendo pertinente para desentrañar el entorno y el aprendizaje del autor e, incluso, para calar en estratos más profundos de la obra. ¿Es el Laa una «joya de mudejarismo literario», obra de un «sufí cristianizado», ${ }^{2}$ como lo sugería Américo Castro, fiándose en las declaraciones de Llull sobre la existencia de un original en árabe? Careciendo de las más elementales competencias del arabista, no nos aventuraremos en un estudio - donde ha zozobrado más de un investigador-de sus fuentes islámicas. Pero lo que sí esta a nuestro alcance, consiste en realizar un primer careo de sus posibles fuentes cristianas, ${ }^{3}$ que desglosaremos en latinas -o sea patrísticas-, neolatinas y vernaculares. En la medida de lo posible, intentaremos descartar lo que constituye un patrimonio común, «los bienes mostrencos» de la conciencia medieval, para ceñirnos a influencias claramente delineadas, reconociendo la parte de subjetividad que ello implica. Nuestro texto de referencia será, por supuesto, la magnífica edición de Albert Soler, con 1a salvedad de que haremos constar asimismo la numeración tradicional. ${ }^{4}$

2 Américo Castro, La realidad histórica de España, México, Ed. Porrúa, 1954, p. 302 y 308. Para un balance, razonablement escéptico, de la influencia suff: Dominique Urvoy, «Les emprunts mystiques entre Islam et Christianisme et la véritable portée du Llibre d'amic», Estudios lulianos 23, (1979), pp. 37-44.

3 Por figurar ya en nuestra tesis doctoral, no realizaremos un inventario de la fuentes bíblicas, a menudo simples alusiones, que afectan a un mínimo de setenta y seis apartados, o sea más de una cuarta parte de la obra, lo que, ya de alusiones, que afectan a un mínimo relativiza la eventual influencia islámica en dicho opúsculo: Vincent Serverat, L'être et la joie. La philosophie de Ramon Llull dans le Llibre d'amic e amat, Greifswald, Reineke, 1993, pp. 447-461.

4 En efecto, no creemos que la nueva numeración aporte una solución definitiva, caso de que sea posible, al espinoso problema de la división del texto en secuencias y, como corolario, al de su suma total que remite, como se sabe, a los días del año (¿pero qué tipo de año?). El editor adopta, en casos litigiosos, un criterio de delimitación que nos parece franquear las puertas a cierto subjetivismo: «cada versicle constitueix una certa unitat temàtica i argumental que fa un sentit complet». (A. Soler, en Laa, o.c., p. 53). A nuestro modesto entender, sería preferible adoptar, en algunos casos, criterios menos «materiales», más «formalistas» y estilísticos. Por tomar un ejemplo, no sería absurdo desdoblar el apartado 129/133-134, basándose en una técnica luliana usual para el inicio de versículo, a saber un verbo en imperfecto (cuyo semantismo resume la acción y enmarca, de modo panorámico, los pretéritos subsiguientes), seguido del sujeto. 


\section{LA PATRÍSTICA LATINA}

Como es de esperar, entre las fuentes latinas del Laa predominan, de modo abrumador, los textos cristianos de la Antigüedad tardía, si bien no puede descartarse alguna reminiscencia de la latinidad clásica, y pensamos en un pasaje de Cicerón, reformulado, y sin duda difundido en el medievo, por San Ambrosio de Milán (c.340-397). En el De officiis ciceroniano, se bosqueja, en efecto, un retrato moral de Escipión el africano, que estriba en la doble paradoja del «descanso atareado» y de «la soledad acompañada»:

numquam se minus otiosum esse quam cum otiosus, nec minus solum quam cum solus esset. Qux declarat illum et in otio de negotiis cogitare et in solitudine secum loqui solitum, ut neque cessaret umquam et interdum colloquio alterius non egeret. ${ }^{5}$

Frente a este texto, Ambrosio de Milán va a situarse en una lógica de emulación entre el héroe pagano y el santo de la revelación bíblica, encareciendo el modelo de Moisés con respecto al de Escipión: cuando moraba en el desierto, el legislador hebreo no se contentaba con planear sino que realizaba prodigios y, además, no sólo vivía en compañía de sí mismo sino de Dios:

Non ergo primus Scipio sciuit solus non esse cum solus esset nec minus otiosus cum otiosus esset; sciuit ante ipsum Moyses qui cum taceret, clamabat, cum otiosus staret proeliabatur, se etiam de hostibus quos non contingerat, triumphabat [...]. Et in illa solitudine qui cum eo loqueretur no deficit, unde et David ait: «Audiam quid loquatur in me Dominus Deus». Et quanto plus est cum aliquo Deus loquatur, quam ipse secum? ${ }^{6}$

En el Laa, Ramon Llull desarrolla sobre todo la paradoja de la «soledad acompañada» (solus non esse cum solus esset), siguiendo la relectura ambrosiana de una soledad que consiste, no en estar a solas consigo mismo sino con Dios, a lo que se añade un corolario temático, por contraste, el de la, «compañía solitaria», o sea la soledad del contemplativo rodeado del gentío mundano (tot sol enfre les gents):

[46/45] Desirà l'amich soliditat e anà estar tot sol per ço que agués companya de son amat, ab lo qual està tot sol enfre les gents.

[47/46] Estava l'amich tot sol, sots l'ombra d'un bell arbre. Passaren hòmens per aquel loch e demanaren-li per què stava sol; e l'amich respòs que sol fo con los ach vists e ohits, e que d'abans era en companya de son amat.

[348/356] Anava l'amich consirós de son amat e atrobà en la via grans gents e grans companyes que li demanaven de noves. E l'amich, per ço cor atrobava plaer en son amat, no respòs a ço que li demanaven e dix que per ço que no.s lunyàs de son amat no volia respondre a lurs paraules. 
Valiéndose del políptoton (annominatio) a partir del radical sol, en una gran variedad de flexiones, Ramon Llull multiplica los sentido equívocos en torno a la paradoja fontal de la «soledad acompañada»:

[292/299] [...]. Cor àls no est mas amors, en les quals me fas estar sol e ab companya de tes amors e de tos honraments. Car tu est sol en mi sol, qui son solitari ab mos pensaments, con la solitat tua, sola en honors, m'haja sola a loar e honrar ses valors, sens temor desl desconeixents qui no t'an sol en lurs amors.

La predilección por la paradoja de la «soledad acompañada, (tu est sol en mi sol) no quiere decir, sin embargo, que haya desaparecido el segundo tema ciceroniano, el del «descanso atareado» (in otio de negotiis cogitare). Y no es sin duda fortuito que la annominatio de sol se concatene, acto seguido, en la de solaç:

[293/300] Solaç est, amat, de solaç; per què en tu han solaç mos pensaments en ton solaç [...].

Lo que sí se da es cierto olvido del negotium, que pasa a un segundo plano, para centrarse en el otium contemplativo, en congruencia con la intención del Laa, una compilación de plegarias abreviadas para cada día del año. Parece como si Ramon Llull, descartando el negotium, no hubiera cruzado sino tres de las cuatro circunstancias vitales - solus, cum Deo, et otiosus-en un tema único, el solaz de la soledad contemplativa, lo que se plasma en la paronomasia solaç/solitat:

[239/245] —Digues, foll, què és solitudo?

Respòs: - Solaç e companya d'amich e amat.

-E què és solaç e companya?

Respòs que solitudo estant en coratge d'amich qui no membra mas tan solament son amat. [340/349] [...] E és qüestió per qual de tots quatre fo mills asolaçat l'amich en son amat.

Cerrando este primer paralelo, nos limitaremos a señalar que el término solaç, por su semantismo, se acerca a la expresión fruitur gaudio, que utiliza Guillermo de Saint-Thierry, en vez de otium, cuando retoma, en su Epistola aurea, el tema ciceroniano-ambrosiano de la «soledad acompañada». ${ }^{7}$

En nuestro recorrido de la patrística latina, hay cierta lógica en pasar de Ambrosio de Milán a la imponente figura del que fuera su aventajado catecúmeno, Agustín de Hipona (354-430). Su impronta, directa o indirecta, en el $L a a$, es tan capilar y ramificada que hace imposible, en el marco de este artículo, un estudio, o incluso un simple bosquejo, del conjunto de tesis agustinianas que encierra la obra. ${ }^{8}$ Por dicho motivo, nos limitaremos a dos calas, la primera en la con-

7 «Vere enim solus est, cum quo Deus non est. Cum quo enim Deus est, numquam minus est solus, quam cum solus est. Tunc enim libere fruitur gaudio suo, tunc ipse suus es ad fruendum Deo in se, et se in Deo»: Guillermo de Saint-Thierry, Epistola ad fratres de Monte-Dei, cap. 19, en M.-M. Davy (ed.), Un traité de vie solitaire [...], Paris, Vrin, 1940, p. 78.

8 Por ejemplo la serie $\$ \$ 289 / 296-293 / 300,296 / 303-304 / 311$, bien pudiera depender de los Soliloquia agustinianos, al basarse en una meditación sobre las perfecciones divinas, enunciadas, al modo de una doxología litúrgica, mediante una multiplicidad de preposiciones: «me tens enamorat, ab tes amors, qui m'an enamorat de tes amors, per tes amors e en tes amors» ( $\$ 292 / 299)$. Cfr. Agustín de Hipona, Soliloquia, L.1, 3, dans Opera, París, 1836-1838 (=Opera); vol. I, c. 599 (en particular, pour veritas y Laa $\$ 304 / 311$ ). 
cepción por así decir «racionalista» del quehacer teológico, la segunda en la interioridad como vía de acceso a Dios.

En el versículo 191/197, Ramon Llull glosa poéticamente el programa agustiniano de una feinteligencia, credo ut intelligam, lo que traduce el mallorquín, situando al amante en una encrucijada espiritual, enfre creença e intelligència. ${ }^{9}$ Como una lanzadera de telar, el alma del creyente se mueve en un perpetuo vaivén, entre la escucha dócil de la predicación cristiana y la indagación de razones, que le permitan alzar su creencia al rango de una inteligencia de la fe:

[191/197] Tant amava l'amich a son amat, que de tot ço que li dehia lo crehia. E tant lo desirava entendre, que tot ço que n'ohia dir volia entendre per rahons necessàrias.

E per aço, la amor de l'amich estava enfre creença e intel.ligència.

Entre las numerosas formulaciones del «racionalismo» agustiniano, seleccionaremos las que engloban dos temas presentes en el versículo luliano: una dialéctica entre fe e inteligencia (fides qucrens intellectum), a la que se añade una asimilación del acto de fe a la audición.

Quamvis enim nisi aliquid intelligat, nemo poteste credere in Deum; tamen ipsa fide qua credit sanatur, ut intelligat ampliora. Alia sunt enim quæ nisi intelligamus, non credimus; et alia sunt quæ nisi credamus non intellegimus. Nam cum fides sit ex auditu, auditus enim per verbum Christi [Rom. X, 17]; quomodo credit, prædicanti fidem, qui ut alia taceam, linguam ipsam quam loquitur non intelligit? Sed nisi essent rursus, aliqua quæ intelligere non possumus, nisi ante credamus, propheta non diceret, nisi credideritis, non intelligetis [Is. VII, 9]. ${ }^{10}$

Tanto Ramon Llull como San Agustín sitúan el nacimiento de la fe en la escucha de la predicación cristiana, fides ex auditu, lo que glosa Ramon Llull en clave de amor místico: Tant amava l'amich a son amat, que de tot ço que li dehia lo crehia. Resulta evidente, sin embargo, que las formulaciones agustinianas son objeto de cierta actualización, en el versículo citado, y nos referimos sobre todo a la controvertida expresión rahons necessàrias que entronca con una terminología posterior, en concreto con el racionalismo teológico de San Anselmo de Canterbury (1033-1109) y Ricardo de Saint-Victor (+1173), que promociona lo que eran simples analogías (similitudines) o congruencias (rationes probabiles), en San Agustín, al rango de pruebas apodícticas del dogma cristiano: «non modum probabilia imo etiam necessaria argumenta». ${ }^{11}$

Junto al paralelo creencia/audición, se encuentra en el Laa otra correspondencia sensorial que vincula la inteligencia con la visión ( $\$ 258 / 265,277 / 284)$ y, asimismo, un pasaje ( $\$ 327 / 334$ ) que encierra la totalidad del tema, o sea un debate sensorial entre audición y visión, que sirve para ilustrar, como ya sabemos, una oposición entre dos campos de la teología, positiva per auctoritates 0

9 Para la problemática de la creencia-inteligencia en el Laa, nos permitimos remitir de nuevo a: Serverat, L'être et la joie [...], op. cit., pp. 229-235.

10 Agustín de Hipona, Enarratio in Psalmos, Sermo 18, dans Opera IV, c. 1889. La formulación más conocida, aunque no se refiera a la fe como escucha, se halla en: Sermo 43, «Nisi credideritis, non intelligetis», ibid., V, c. 303.

11 Ricardo de Saint-Victor, De Trinitate, L. 1, cap. 4, PL 196, 891 C. Para otra formulación clásica del «racionalismo» teológico: Anselmo de Canterbury, De fide Trinitatis, præfatio, PL 158, c. 259-261. 
especulativa per rationes. ${ }^{12}$ Señalemos de paso la presencia de otro doctrina agustiniana -omnipresente en el Laa -, la concepción del alma como una «trinidad», ${ }_{13}^{13}$ donde la actividad intelectiva (enteniment) se compenetra con la afectividad (volentat) y la memoria (remembrament):

[327/334] Hoÿa l'amich paraules de son amat, en les quals lo vehia son enteniment per ço cor la volentat havia plaer d'aquel ohiment e lo remembrament membrava les virtuts de son amat e los seus prometiments.

Lo que importa para nuestra argumentación, en el texto luliano, es que ofrece un esquema más completo, con una doble correspondencia entre creencia-audición e inteligencia-visión, mientras que, en el obispo de Hipona, sólo hemos hallado el primero de ambos paralelos. Para encontrarnos con precedentes de dicha dualidad sensorial, hemos tenido que rastrear en la posteridad agustiniana, por ejemplo en Ricardo de Saint-Victor que contrapone dos trilogías, la una positiva o «fideista» (exponere, audire, credere), y la otra especulativa o «racionalista» (proponere, videre, intelligere), con ocasión de una controversia sobre la profecía del Emanuel (Isaías VII, 14-25). Si el victorino parece colocar la fe-audición por encima de la inteligencia-visión, ello se debe a una argumentación de tipo irónico, donde propone un acto de fe - 0 sea de autoridad - a un contrincante « in-inteligente», en el que no hacen mella los argumentos racionales, aquí un exégeta cristiano partidario del literalismo judaizante:

Sicut ergo superius diximus, qui non potest intelligere proponentem, audiat vel exponentem. Qui non habet oculos ad videndum, habeat aures ad audiendum. Numquid, et vos cæci estis, ut surdi sitis? Quod non potestis intelligere numquid non potestis credere? ${ }^{14}$

Cerraremos este apartado, disculpándonos ante el lector por nuestro desafuero a la cronología, al haber incluido a un autor del siglo XII en la rúbrica de la Patrística, pero nos parecía algo artificial separar, en nuestro estudio del «racionalismo teológico», el momento inaugural agustiniano y su recepción medieval.

A diferencia de otras ramas de la filosofía cristiana que privilegian el acceso «cosmológico» hacia Dios, e rebus creatis, San Agustín explora asimismo una vía «sicológica» que, partiendo de

12 Se leen otros debates entre visión y audición ( $\$ 327 / 335)$, pero que no se encuentran vinculados con la problemática creencia/inteligencia.

13 Para un inventario: Serverat, L'être et la joie [...], op. cit., p. 447-461 (figura S del Arte luliano). Un reciente estudio sobre la génesis de esta doctrina, en: Josep E. Rubio, «La figura $S$ de l'art lul.liana i el Llibre de contemplació en Déu», Llengua \& Literatura 7, (1996), pp. 61-89. Para algunos precedentes de dicha concepción del alma, una y compuesta de tres facultades co-sustanciales: Agustín de Hipona, De Trinitate, L. 10, cap. 17-19/11-12, Opera VIII, c. 13651368 ; Bernardo de Clairvaux, Sermo «de diversis» 45 (102), 1, PL 183, c. 667 ; del mismo autor Sermones in Cantica, Sermo 11, 5-6, ibidem, c. 826 ; Guillermo de Saint-Thierry, De natura et dignitate amoris, 5, en M.-M. Davy (ed.), Deux traités de l'amour de Dieu, Paris, Vrin, 1953, p. 76-77, etc.

14 Ricardo de Saint-Victor, De Emmanuele, PL 196, c. 643-D. La antítesis entre proponere rationes et exponere fidem se asemeja a la contraposición luliana entre entender y mostrar, teología especulativa y teología positiva: Laa, § 353/361. Parece incluso que la primera mención a la «teología positiva» deba atribuirse a Llull, por influencia islámica: Charles Lohr, «Ramon Llull —-teología positiva—árabes», Estudios lulianos, 17 1973, pp. 113-123. 
una exploración del espacio interior o «intrasubjetividad», desemboca en la «intersubjetividad» entre el hombre y Dios: ${ }^{15}$

Noli foras ire foras, in teipsum redi; in interiore hominis habitat veritas. ${ }^{16}$

No nos extenderemos demasiado en este apartado, porque las confluencias entre Agustín y Ramon Llull fueron apuntadas ya, hace mas de medio siglo, por Manuel de Montoliu, ${ }^{17}$ a partir del conocido pasaje de los Soliloquia «Noverim Te, noverim me», que parece glosar el mallorquín en $13 / 12$ y $341 / 349 .{ }^{18}$ En ambos casos, el acceso del hombre a Dios se efectúa, no por la mediación del universo visible, sino por la vía agustiniana de la interioridad: el alma conoce a Dios en sí misma y se reconoce a sí misma en Dios:

[13/12] Digues, foll per amor, ¿e qual cosa és pus vesible: o l'amat en l'amich o l'amich en l'amat?

Respòs e dix que l'amat és vist per amors, e l'amich per suspirs e per plors e treballs e dolors.

Dicho itinerario interior desemboca en una experiencia contrastada, a la vez el amor de Dios y un agudo sentido de la indigencia humana, con la salvedad de que Llull la expresa, con categorías, ya no ascéticas, sino extraídas del amor cortés: per suspirs e per plors e treballs e dolors. En el versículo 341/349, más metafísico y menos «cortés», la referencia agustiniana se presenta más bien como un telón de fondo, sobre el que se inscriben otros temas, ora vinculados con el «socratismo cristiano» (conexença de si mateix), ${ }^{19}$ ora dependientes de una koinè mística (el alma como speculum Dei), difícilmente atribuibles a una fuente precisa:

[341/349] Esguardava l'amich si mateix per ço que fos mirall on veés son amat. E sguarda son amat per ço que li fos mirayll on agués conexença de si mateix.

E és qüestió a qual dels dos miralls era son enteniment pus acostat.

En anteriores trabajos, habíamos señalado, entre las alusiones bíblicas del Laa, el tema sálmico de los impíos que apostrofan, con sarcasmo, al creyente: Ubi est Deus tuus $?^{20}$

15 Resumimos a lo extremo lo que se halla más ampliamente desarrollado en: Serverat, L'être et la joie [...], o.c., pp. 114-126, 297-305, 385-392.

16 Agustín, Liber de vera religione, cap. 72/39, Opera I, c. 1246. La misma idea, en el conocido pasaje de Las Confesiones (L. 10, cap., 27/38): «Sero te amavi, pulchritudo tam antiqua et tam nova!, sero te amavi! Et ecce intus eras, et ego foris, et ibi te quaerebam; et in ista formosa quae fecisti, deformis irruebam. Mecum eras, et tecum non eram. Ea me tenebant longe a te, quae si in te non essent, non essent». Ibidem, I, c. 321. La reminiscencia de Las Confesiones es más literal en una obra anterior: Ramon Llull, Llibre de contemplació, cap. 5, $\S 15-16$, dans Obres essencials $(=O E)$, Barcelona, Ed. Selecta, 1957-1960, vol. 2, p. 115-a.

17 Montoliu, Manuel de, «Ramón Llull, trobador», Homenatge a Antoni Rubió $i$ Lluch, en Estudis universitaris catalans, 21 (1936), pp. 372-373.

18 Vid. asimismo: Laa, $\S \S 24 / 23,218 / 224$.

19 Para el socratismo cristiano, remitimos al ya clásico: Gilson, E., L'esprit de la philosophie médiévale, París, Vrin, 1969, p. 214-233.

20 Serverat, L'être et la joie [...], o.c., pp. 448-449. Nuestra referencia era Sal. 79 (78), 10, a la que se puede añadir Sal. $42-43$ (41-42), 11 ; y, en otra modalidad, Sal. 14 (13) ; 53 (52), 1. 
[24/23]. Demanaren a l'amich on era son amat.

Respòs: Ve'l-vos en una casa pus noble que totes les altres nobilitats creades. He ve'l-vos en mes amors e en mos languiments e en mos plors.

En el texto aducido, así como en $\S 52 / 51$, la respuesta del amigo manifiesta bastantes semejanzas con la exégesis por San Agustín del salmo 41, quien sitúa en el hombre la morada de Dios: «tabernaculum enim Dei in terra, homines sunt credentes». No es en la creación visible donde se debe buscar la presencia del Amado, sino en su más noble morada, una casa pus noble que totes les altres nobilitats creades, entrañado por así decir en el ser del amigo. ${ }^{21}$

Sería, sin duda, erróneo absolutizar, tanto en San Agustín como en Ramon Llull, dicho itinerario interior, olvidando los condicionantes del discurso y del género. En los tratados doctrinales, se puede practicar la «extraversión», desarrollando las analogías ejemplaristas entre el Creador invisible y su creación visible, mientras que el mismo autor, en obras de espiritualidad, tenderá a privilegiar la vía de la introversión, en la línea del llamado socratismo cristiano. ${ }^{22}$

Dando un salto de dos siglos, ya en los linderos de la época altomedieval, vamos a interesarnos por San Gregorio Magno (ante 540-604), el cual, en su comentario a la parábola de la viña y de los sarmientos (Juan, XV, 12-16), se sirve de la alegoría del árbol, para explicar la primacía de la caridad (radix) sobre las demás virtudes (rami):

Ut enim multi arboris rami ex una radice prodeunt, sic multæ virtutes ex una charitate generantur. Nec habet aliquid viriditatis ramus boni operis, si non manet in radice charitatis. Præcepta ergo dominica et multa sunt, et unum: multa per diversitatem operis, unum in radice dilectionis. ${ }^{23}$

En su párrafo $250 / 256,{ }^{24}$ el Laa desarrolla una doctrina similar, recurriendo asimismo a la alegoría del árbol, y que contrapone la multiplicidad de virtudes cristianas (diversses sements) y su unidad, ya no «radical» sino terminal ( $u$ n fruyt), que cabe identificar con la caridad:

[250/256] Sembrava l'amat diversses sements en lo cor de l'amich, d'on nexia, fullava efloria e granava un fruyt tan solament.

E és qüestió si d'aquel fruyt poden néxer diversses sements.

A pesar de las diferencias indiscutibles que median entre ambos textos, encontramos un cañamazo común, compuesto por la alegoría del árbol y, sobre todo, una dialéctica que opone diversidad de virtudes y unidad de la caridad: multa per diversitatem operis, unum in radice dilectionis. Ciertamente, la expresión luliana resulta más enigmática y sugestiva (en congruencia con el sub-

21 Agustín de Hipona Enarrationes in Psalmos, ps. 41, 7-9, Opera V, c. pp. 506-510.

22 A menudo, el conocimiento propio corresponde a un primer grado en el ascenso hacia Dios, así, por ejemplo, en Ricardo de Saint-Victor, el hombre abandona Egipto (el mundo) por la soledad del desierto (su interioridad), de donde pasa al encuentro con Dios: De exterminatione mali et promotione boni, Tr.1, cap. 4, PL 196, c. 1076 A.

23 Gregorio Magno, XL Homiliarum in Evangelia libri duo, L. 2, hom. 27, Patrologia latina $(=P L) 76$, c.1205: cfr. asimismo Romanos, 11, 16. Para otro precedente gegoriano en el Laa, vid. nota 29 infra.

24 Existe un parentesco temático entre este exemplum y los $\S \S 84 / 85,88 / 89$. 
género del poema, un exemplum-acertijo), por esa mịsteriosa multiplicidad de simientes que fructifican en unicidad de fruto, lo que atenta a todas las leyes de la generación vegetal. A nuestro entender, la alteración, o más bien la «re-creación» luliana, puede explicarse, porque el filósofo mallorquín se sitúa aquí en la lógica de un itinerario espiritual: primero, el estadio ascético de las virtudes (diversses sements), y después la vida mística, como una suerte de reductio ad unum o recapitulación de todos los principios morales en el amor del amado (un fruyt tan solament). Es en el segundo miembro, un fruto que produce diversas simientes, donde la formulación se asemeja más a su paralelo gregoriano, una raíz - la caridad - que se despliega en un tupido ramaje de virtudes y de buenas obras.

Aun dando por supuesta dicha filiación doctrinal para el poema $250 / 256$, no puede colegirse de ello una influencia más amplia de San Gregorio Magno en la espiritualidad luliana, al estar dicho fragmento muy difundido en los florilegios para predicadores, sin ir más lejos en el tan manoseado Manipulus florum de Tomás de Irlanda (rúbrica «charitas», § 16). En realidad, trátese de una fuente - lo que nos parece bastante probable — o de una simple convergencia temática, lo esencial radica en que el fragmento gregoriano contribuye a esclarecer el sentido, a delinear los perfiles doctrinales de un poema en prosa, para cuya cabal comprensión no basta con invocar la vaguedad del misterio poético.

\section{LA «INVENCIÓN» DEL AMOR: CISTERCIENSES Y VICTORINOS}

Había barruntado ya Don Marcelino Menéndez y Pelayo, como tantas otras cosas, la huella de Hugo de Saint-Victor en el Laa, si bien la influencia victorina más patente es la de Ricardo, tanto por sus doctrinas trinitarias como por su concepción «racionalista» del saber teológico. Tampoco han faltado estudios sobre la influencia de San Bernardo (1090-1153) y de sus epígonos cistercienses, respaldada por un dato biográfico como son las relaciones bien conocidas de Ramon Llull con la abadía mallorquina de La Real. ${ }^{25}$ Esto dicho, la tarea comparatista, en este campo, se ve dificultada por la continuidad de un lenguaje místico que remonta a fuentes orientales -el SeudoDionisio, Máximo el Confesor, etc.- y que, tras sü momento cisterciense y victorino, se fundirá en el acervo común de la espiritualidad medieval. En el caso de Ramon Llull, uno puede preguntarse sobre todo si tuvo acceso directo a los temas de esa mística por así decir «románica» y monacal, ${ }^{26}$ o bien si los conoce en una remodelación «gótica» y universitaria, más cercana a su tiempo, concretamente la síntesis franciscana de San Buenaventura, una de las fuentes lulianas más a menudo señalada por los estudiosos.

En varias ocasiones, Bernardo de Clairvaux se refiere al Espíritu Santo como un abrazo, osculum, entre dos Amados que son el Padre y el Hijo, al glosar el versículo inaugural del Cantar de los cantares (I, 1): «Osculetur me osculo oris sui $[\ldots] »$ :

25 Para un catálogo de la «librería» de La Real, si bien redactado en 1386, un siglo después del Laa: Jocelyn N. Hillgarth, Readers and Books in Majorca, París, CNRS, 1991, vol. 2, pp. 328-334.

26 Conviene matizar por supuesto una oposición tan tajante, pues, como es notorio, la abadía parisina de SaintVictor constituye un medio intelectual que participa del monacato contemplativo y del mundo escolar parisino, como lo prueba con creces el caso de Pedro Lombardo. 
Nempe si recte Pater osculans, Filius osculatus accipitur, non erit ab se osculum Spiritum sanctum intelligi, utpote qui Patris Filiique imperturbabilis pax sit, gluten firmum, individuus amor, indivisibilis unitas. ${ }^{27}$

En el párrafo 59/58, Llull procede a una ejemplificación narrativa de dicha doctrina: al contemplar el abrazo entre dos amigos, amich, en una vivencia extática, vislumbra un trasunto de la vida trinitaria, sin duda porque deben interpretarse el abrazo y los besos intercambiados como una hipóstasis del Espíritu Santo, nodum amoris:

[59/58] Anava l'amich desirant son amat e encontrà's ab.ii. amichs qui ab amor e plors se saludaren e s'abraçaren e.s besaren.

Smortís l'amich; tant fortment li remembraren los.ii. amichs son amat.

En su intento por esclarecer, en cierta medida, el misterio de la vida trinitaria, San Agustín ya había explorado la estructura del amor que se despliega en una tríada amans, quod amatur y amor, si bien había concluido que, partiendo del amor sui, no puede alcanzarse la trinidad, sino una mera dualidad, por identificarse, en ese supuesto, las personas del amante y del amado. ${ }^{28}$ La tentativa fallida de San Agustín -marginal, por lo demás, con respecto a otras de sus analogías trinitariasserá revisitada, en el siglo XII, tan atraído por la poética y la filosofía del amor. En clave mística, los autores cistercienses metaforizan al Espíritu Santo como un osculum amoris; en clave teológi$\mathrm{ca}$, Hugo de Saint-Victor ${ }^{29} \mathrm{y}$ - con más rigurosa dialéctica- Ricardo van a erigir la estructura ternaria del dinamismo amoroso en núcleo de su pensamiento trinitario. Con gran prolijidad, argumenta el segundo que la plenitud del amor, summe diligendus, no puede concebirse fuera de una estructura ternaria donde cada persona es a la vez amante y amada. ${ }^{30}$ La novedad de Ricardo, con respecto a sus predecesores, nos parece consistir en que combina una analogía trinitaria, de carácter piadoso o místico, con el ontologismo anselmiano del summe cognoscendus que se traspone al summe diligendus. No puede concebirse ni desearse - y no puede por lo tanto no existir- mayor Amor que la condilectio de dos amantes y de un socius. Y, en efecto, son varios los pasajes del $\mathrm{LaO}^{31}$ que ejemplifican dicha estructura trinitaria del Amor, combinada con la vía anselmiana, que confiere, como es sabido, el mayor grado de existencia al mayor grado de ideación cognitiva (lo que corresponde, dicho sea de paso, a la regla de majoritat en la figura T del arte luliano):

27 Bernardo de Clairvaux, Sermones in Cantica, Sermo 8 § 2, PL 183, c. 811. Asimismo en un sermón de diversis: «Per osculum comune est osculantis et osculatum. Si igitur se invicem osculantur Pater et Filius, quid est eorum osculum nisi Spiritus sanctus?»: Sermones de diversis, Sermo 89 (140) §1, PL 183, c. 707.

28 Agustín de Hipona, De Trinitate, L. 9, cap. 2, Opera VIII, c. 1339-1340. Al parecer, no debe descartarse tampoco la influencia de un breve pasaje de Gregorio Magno, donde el pontífice señala a vuela pluma que no puede haber caridad sin pluralidad: XL Homiliarum in Evangelia libri duo, hom. 17, n. 1, PL 76, c. 1139 A.

29 Hugo de Saint-Victor, Eruditionis didascalica Libri VII, L. 3, cap. 23, PL 176, c. 833.

30 Ricardo de Saint-Victor, De Trinitate, L. 3 y 5, passim, PL 196, c. pp. 915-930, 947-968. Su análisis del amor intra-trinitario será prolongado por los franciscanos Alejandro de Hales y San Buenaventura, criticada por Santo Tomás de Aquino (Summa Theologica, Ia, q. 32, a.1 ad 2) y restaurada por Enrique de Gante, al que sin duda conoció Llull en París: vid. Gervais Dumeige, Richard de Saint-Victor et l'idée chrétienne de l'amour, París, PUF, 1952, pp. 105, 161-163.

31 Laa, $\S \S 204 / 210,253 / 260,255 / 262,258 / 265,261 / 268,262 / 269$. 
[204/210] Amor, amar, amich e amat se covenen tant fortment en l'amat que -1. a - actualitat són en essència. E diversses coses són l'amich e l'amat, concordants sens nulla contrarietat e diverssitat d'essència. E per açó és amable l'amat sobre totes altres amors.

Con respecto a Anselmo, comparten Ricardo de Saint-Victor y Ramon Llull una doble originalidad, la de completar, en primer lugar, su matriz teorética, quo magis cogitari non potest, mediante una aplicación axiológica, quo melius..., y, en segundo lugar, la de aplicar dicho argumento ontológico, no sólo a la existencia divina, sino también a los atributos de su esencia (diversitat, concordança):

[258/265] Los secrets de son amat vehia l'amich per diversitat, concordança que li revelavan pluralitat, unitat, en son amat per major conveniment d'essència sens contrarietat.

Situándonos ahora en el plano epistemológico, Ramon Llull parece atenuar sin embargo el valor demostrativo de las «rationes necessarias» del victorino, al aquilatarlas como meras congruencias (de ahí el empleo recurrente del verbo covenir), ${ }^{32}$ más bien que como argumentos de necessitate. En el mismo orden de ideas, se puede notar la expresión «los secrets de son amat vehia l'amich» donde se compagina la tarea de elucidación racional (vehia) con la irreductible opacidad del misterio trinitario (los secrets de son amat).

De menor relevancia, nos parece la adopción por Ramon Llull de un símil bernardino, mesclament d'aygua e de vi, para designar la unión entre el alma.y Dios, ${ }^{33}$ de preferencia a la comparación, tal vez más difundida, entre el hierro candente y el fuego, que entronca con numerosos textos de la patrística griega:

[50/49] Eguals coses són propinqüitat e lunyedat enfre l'amich e l'amat. Cor enaixí con mesclament d'aygua e de vi, se mesclen les amors de l'amich e l'amat; enaixí con calor e lugor, s'encadenen lurs amors; e enaixí con essència e ésser, se convenen e s'acosten.

Señalemos de paso la reticencia luliana, que se verá confirmada más adelante, en adoptar expresiones fuertemente unitivas. Entre Dios y el hombre, la cercanía (propinqüitat) no viene a abolir la distancia ontológica (lunyedat), sin contar que se mantiene la dualidad entre el Amor increado de Dios y el amor creado del hombre, les amors de l'amich e l'amat, por oposición a la tesis - o simple hipérbole- «beguinal» de que el contemplativo ama a Dios con el mismo amor con que Él nos ama.

Como una última cala en las reminiscencias cistercienses del opúsculo luliano, desearíamos analizar una temática poco estudiada hasta ahora en el Laa y que consiste en lo que se podría llamar una comunicación extralingüística, un «elocuente» silencio, cuyos signos son la mirada, los gestos, la indumentaria, etc. Dicho idioma puede darse, sea entre el Amado y el amante $(\$ \S 29 / 28$,

32 Resulta muy patente en otra estrofa: «255/262] -Digues, foll, què fahia ton amat ans que.l món fos? Respòs: Covenia's a ésser per diversses proprietats eternals, personals, infinides, on són amich e amat.»

33 Bernardo de Clairvaux, De diligendo Deo, cap. 10, 28, PL 182, c. 991 
$146 / 151,226 / 233)$, sea entre el amante y la creación material ( $\$ 27 / 26)$, sea, lo que nos parece más significativo para nuestro propósito, entre varios amantes del Amado ( $\$ \$ 149 / 154,168 / 174$, 179/185). Citemos como botón de muestra, a este respecto, el poema siguiente:

[149/154] Encontrà l'amich un scuder qui anava consirós he era magre, descolorit e pobrement vestit; e saludà l'amich dient que Déus l'endreçàs a trobar son amat. E l'amich li demanà en què l'avia conegut; e l'escuder li dix que los uns secrets d'amor revelen los altres e per açò han conexença los amadors los uns dels altres.

La hermeneútica de este versículo nos parece crucial, en términos de ortodoxia 0 , si se prefiere, de eclesialidad, para la espiritualidad luliana en el Laa, obra que fue redactada en un período oscuro de la biografía de Ramon Llull, que estaría marcada, según ciertos indicios, por cierta cercanía a formas de un cristianismo espiritual más bien que sacramental. De existir un trasfondo «espiritual» para el texto citado, se vería confirmado por su proximidad con uno de los pasajes más controvertidos y enigmáticos de la obra $(\$ 151 / 156)$, donde parecen contraponerse una comunidad espiritual de elegidos (spirits d'amor) y una cristiandad carnal. ${ }^{34}$

Uno de los amantes, el escudero, ha reconocido a su compañero de amor sin que medien palabras, pues los uns secrets d'amor revelen los altres. Este mutuo y silencioso reconocimiento entre los amigos de Dios se encuentra en Guillermo de Saint-Thierry (+1148), amigo y biógrafo de San Bernardo, que se incorporó, al final de su vida, a la reforma cisterciense, pasando de los benitos o monjes negros a los bernardos o monjes blancos. En su libro, De contemplatione, se refiere a una misteriosa lengua angélica, sin palabras, mediante la cual se comunican los perfectos, quam linguam nullus novit, nisi Rex angelorum et angeli ejus, et qui sunt ex genere Isrel, et cives Jerusalem.

En su origen, dicho tema pudo nacer como un elogio del silencio y la fraternidad claustral, aunque llevaba en germen, como veremos, la distinción, en el seno de la Iglesia, entre una minoría angélica y una mayoría carnal, o, dicho de otro modo, la comunidad de espirituales y la jerarquía eclesiástica. Absolutizando, con cierta rigidez, las tesis del abad de Saint-Thierry, la beguina Marguerite Porete llamará Sainte-Église-la-Grande a las almas contemplativas y Sainte-Église-laPetite a la institución eclesiástica. ${ }^{35}$ Pero, bástenos de momento, apuntar las afinidades entre la lingua angelorum - hecha de afectos y de semblantes- en Guillermo de Saint-Thierry y la temática luliana de una comunicacion que transciende la indigencia del lenguaje humano: ${ }^{36}$

34 «151/156] Grans osts e grans companyes se són ajustades de spirits d'amor, e porten senya d'amor on és la figura e.l senyal de lur amat. E non volen mena en lur companya null home qui sia sens amor, per ço que lur amat no y prenga desonor.» Mucho se ha escrito sobre las afinidades de Llull con el franciscanismo espiritual: Por estar centrado sobre la novela Blaquerna, donde se halla engastado el Laa, me permito remitir a mi estudio sobre el particular: Serverat, «Homo novus. Un ressort du discours utopique dans le Blanquerne de Raymond Lulle», dans D. Buschinger y W. Spiewok (ed.), Discours et figures de l'Utopie au Moyen Age, Greifswald, Reineke, 1994, pp. 119-152.

35 Marguerite Porete, Le miroir des âmes simples et anéanties, cap. 19, 43, M. Huot de Longchamp (trad.), París, Albin Michel, 1997, pp. 79-80, 107-108.

36 No podemos profundizar aquí en la relaciones que se darían entre este tema monástico -el sermo interior o lengua del alma- y la doctrina luliana de un sexto sentido o affatus, para lo que remitimos al trabajo brillantemente pionero de: Mark D. Johnston . Estudios lulianos, 30 (1990), pp. 21 -23 (el lenguaje es intrasubjetivo antes de ser intersubjetivo). Para la relación sujeto/sujeto, en vez de sujeto/objeto en el acto de conocimiento, vid. asimismo: Ramon Llull, Libre de demonstracions, L.4, cap. 41, «de secrets», Obres de Ramon Llull XV, Palma, 1930, pp. 565-568. 
Inter se autem sapientes habent quondam privatam gratiam, et quandam linguam angelicam, lingua angelorum, qua inter se loquuntur mutuis affectibus, spirituali quandam gratiam, communicantibus in hoc ipsum exterioribus aspectibus: quam linguam nullus novit, nisi Rex angelorum et angeli ejus, et qui sunt ex genere Isræl, et cives Jerusalem. ${ }^{37}$

En virtud de este lenguaje espiritual, sólo el contemplativo puede reconocer y juzgar al contemplativo (e per açò han conexença los amadors los uns dels altres), lo que tiende, en sus formulaciones más radicales, a negar la mediación y el poder de discernimiento de la Iglesia en el reducto de la vida espiritual. Frente a lo que se considera ingerencia del teólogo y del canonista, el cristiano espiritual aduce la doctrina de la lingua angelorum, respaldada por el pasaje paulino: «Spiritualis autem judicat omnia, et ipse a nemine judicatur» (I ${ }^{\mathrm{a}}$ Cor, II, 15). En el caso de Llull, resulta difícil pronunciarse sobre el sentido de dicho tema - el mutuo reconocimiento entre los spirits d'amor-, el cual puede interpretarse, sea en clave panegírica, como en Guillermo de Saint-Thierry, sea en clave doctrinal, como en la galaxia del cristianismo espiritual. ${ }^{38}$ Bajo reserva de pesquisas ulteriores, tenemos la impresión de que la espiritualidad luliana, tentada en el Laa por temas afines al «libre espíritu de amor», fue evolucionando hacia formulaciones más eclesiales y sacramentales -piénsese, por ejemplo, en sus insistencia sobre la confesión-, hasta tal punto que su Arbre de filosofia d'amor bien pudiera considerarse, en ciertos aspectos, como un alegato anti-beguinal. ${ }^{39}$

Desearíamos cerrar nuestra encuesta sobre las filiaciones cistercienses y victorinas, interesándonos por el motivo de la «nube luminosa». Sacado de la cantera bíblica (Éxodo, XIV, 20; XXIV, 17), el símil-oximoron de la nube arrebolada suele designar un estado intermedio, iluminativo, de la vida mística, posterior a los preliminares purgativos y anterior a la consumación unitiva. En un primer tiempo, presentaremos la versiones respectivas del motivo en Ramon Llull y en Ricardo de Saint-Victor:

[118/122]. Enlumenà amor lo nuvolat qui.s mès enfre l'amich e l'amat, e féu-lo enaixí lugorós e resplendent con és la luna en la nit e l'estel en l'alba e lo sol en lo dia e l'enteniment en la volentat.

E per aquel nuvolat tan lugorós se parlen l'amich e l'amat.

In medium nebulæ Moyses ingreditur, quando humana mens ab illa divina luminis immensitate absorpta, summa sui oblivione sopitur; ita ut mirari valeas, et juste mirari debeas quo-

37 Guillermo de Saint-Thierry, De natura et dignitate amoris, cap. 51, en M.-M. Davy (ed), Deux traités [...], o.c.,, p. 133. Para esa misma comunicación silenciosa, pero entre espirituales y principiantes: Epistola ad fratres de Monte-Dei, cap. 82, en M.-M. Davy (ed.), Un traité de vie [...], o.c., pp. 127-128.

38 Vid. Marguerite Porete, Le miroir [...], cap. 139, o.c., p. 234.

39 Queda por realizar un estudio comparativo entre el Arbre de filosofia d'amor y el Miroir des âmes simples de Marguerite Porette, dos obras que se asemejan por su forma dialogal, semi-teatralizada, y por el tema central, o sea una controversia entre scientia y amantia. Esto dicho, la obra de Llull (París, 1298) parece ser anterior al Miroir cuyo término ad quem de redacción -su condena por el obispo de Cambrai- debe fijarse a 1306. Sin entrar en el capítulo -más sustancial- de las discrepancias, nos llama la atención cierta contaminación superficial de Llull por doctrinas afines al «libre espíritu» (en realidad, una versión radicalizada de temas cistercienses), aunque dichas formulaciones están a menudo rectificadas en otros lugares de la obra: exaltación del «puro amor» y devaluación consiguiente de lä esperanza teologal (I, 2, $\S 15$ ) ; deseo de unión a Dios sine medio (IV, 3, \$ 9); voluntad de superar los medios ascéticos, como la mortificación, la cual llega a concebirse como un obstáculo entre el contemplativo y Dios (IV, $3, \S 7$ ); la indiferencia al bien y al mal espirituales del prójimo, con una pasividad apostólica, bastante inesperada en le caso de Llull $(\mathrm{IV}, 3 ; \S 2)$ : Arbre de filosofia d'amor, OE II, p. 29, 48-49 ; cfr. Marguerite Porete, Le miroir [...], cap. 16, 49, o.c.,, p. 76-77, 114. 
modo concordet ibi nubes cum igne, et ignis cum nube: nubes ignorantiæ, cum nube illuminata intelligentiæ. Ignorantia et oblivio notorum et expertorum, cum revelatione et intelligentiæ, prius ignotorum et eousque inexpertorum. Nam uno eodemque tempore humana intelligentia, et ad divina illuminatur, et ad humana obnubilatur. ${ }^{40}$

Lo que está en juego asimismo, en el topos de la nube iluminada, es uno de los principales conflictos entre teólogos y místicos, que se enfrentan alrededor de la doctrina, sea de una visión directa e inmediata de Dios (facie ad faciem), sea de una visión indirecta y mediata (cum medio o cum specie). En el versículo luliano, de modo más patente que en Ricardo de Saint-Victor, se adopta la doctrina de la visión cum medio, puesto que no se disipa la nube - sólo se arrebola- entre el hombre y Dios: e per aquel nuvolat tan lugorós se parlen l'amich e l'amat. Por supuesto, cabe preguntarse si la experiencia luliana del nuvolat lugorós tiene un carácter señero, o si se trata de una etapa hacia una vivencia más inmediata de Dios, ya no a través de la nube arrebolada, sino en la claridad, cuya posibilidad parece reconocerse en el Laa. ${ }^{41}$ En el marco del presente trabajo, nos limitaremos a dejar constancia del problema, siendo consciente de que su elucidación, en la obra de Ramon Llull, exigiría una monografía de cierta amplitud, tanto más cuanto que convendría distinguir varios supuestos primordiales en la relación entre el hombre y Dios, según se trate de un dinamismo cognitivo (scientia) o volitivo (amantia), ${ }^{42}$ situado en el orden de la naturaleza o de la gracia - a su vez teologal (lumen fidel) o contemplativa (lumen contemplationis) - , y, por último, en la condición terrenal o ultraterrenal (lumen gloria) del hombre.

El motivo de la nube luminosa, asimismo, puede servirnos de ejemplo paradigmático, valga el pleonasmo, para tomar conciencia de los límites inherentes al método de las filiaciones y paralelos. En efecto, el sentido profundo de la imagen sólo puede desentrañarse, restituyendo dicha elemento en el marco de un sistema, una economía más amplia de la vida espiritual. Tanto Ramon Llull como Ricardo de Saint-Victor parecen inscribirse en un mismo sistema, que progresa «de la tiniebla hacia la luz», por el peldaño de la nube luminosa, o sea una mística afirmativa, catafática o solar. ${ }^{43}$ En el sistema rival -esencialmente griego, el de Gregorio de Nisa y del Seudo-Dionisiose asciende, al contrario, «de la luz hacia la tiniebla», según los presupuestos de la mística negativa, nocturna o apofática, que la cristiandad latina parece asumir más tardíamente, por ejemplo en la obra del maestro Eckhart. ${ }^{44}$

40 Ricardo de Saint-Victor, Benjamin major, L. 4, cap. 22, PL 196, c. 165.

41 Incluso en sus pasajes más unitivos, Ramon Lluli suele mantener, sin embargo, la distancia entre el hombre y Dios: el amante no se funde con el Amado, sino con una de sus epifanías creadas, por ejemplo la luz ( $\$ \$ 96 / 99,199 / 205$ ). Para un estado de la cuestión en el Laa, que incluye las aportaciones de otros estudiosos: Serverat, L'être et la joie [...], o.c., pp. 152-159, 179-181.

$42 \mathrm{Tal}$ vez gracias a sus estancias en París, Ramon Llull pudo liegar a formulaciones más técnicas y matizadas en materia de unión immediata o mediata (cum medio, cum specie) a Dios, por ejemplo en: Arbre de filosofia d'amor, IV, 3, $\S 9, O E$ II, p. 49-b.

43 Para el ascenso de la nube a la luz: Ricardo de Saint-Victor, De IV gradibus violentce charitatis, PL 196, 1218 C-D, 1219 C-D ; Benjamin major, L. 4, cap. 22-23, ibid., c. 164-168. Queda por hacer un estudio de las críticas lulianas a la teología negativa, sea especulativa o mística, para el que aportamos algunos elementos en: Serverat, L'être et la joie [... ], o.c., p. 328-330. Al contrario, la mística de Guillermo de Saint-Thierry tendría un carácter más bien negativo, al subrayar la inaccesibilidad divina: Epistola ad fratres de Monte-Dei, cap. 118, o.c., p. 153-155.

44 Gregorio de Nisa, Vita Moysis, en Patrologia graca 44, c. 375-378. Para un estudio: Jean Daniélou, Platonisme et théologie mystique, Paris, Aubier, 1944, pp. 201-210. 
Aquí se nos ofrece pues el ejemplo mismo de un tema similar —el estado mediano de la «nube luminosa»- que se ve afectado de un sentido dispar, según se identifique la suprema experiencia unitiva con la iluminación del alma o, al contrario, con la tiniebla. Ensanchando nuestra perspectiva, lo que se plantea aquí es nada menos que el estatuto de la espiritualidad victorina y luliana. ¿Puede calificarse de mística stricto sensu esa contemplación afirmativa y solar que no se incorpora las noches del canon sanjuanista? Por nuestra parte, nunca hemos pensado que pueda hablarse, en sentido estricto y experiencial, de mística luliana - y tal vez incluso victorina-, sino de espiritualidad, contemplación, amor de Dios etc. ${ }^{45}$ Nos contentaremos con dejar constancia aquí de este debate fundamental, apresurándonos a cerrarlo, por tratarse de una cuestión, no sólo espinosa, sino tal vez incluso insoluble.

\section{LA LITERATURA ROMANCE}

Entre las fuentes del Laa, sugirimos en su día la histoira de Ami et Amile, elogio de una fiel amistad caballeresca, cuyas versiones medievales se sitúan en el cruce, o colisión, entre dos polos genéricos, la épica y la hagiografía ficcional. Al pasar muy pronto dicha legenda a los ejemplarios homiléticos, Ramon Llull pudo conocerla, sea en su modalidad amplia de cantar sea en el formato breve del exemplum. ${ }^{46}$

En el episodio que nos interesa, el conde Amile es denunciado por haber compartido el lecho de la hija de Carlomagno. Su íntimo amigo —en realidad un alter ego gemelar-, el conde Ami suplantará su identidad en los arriscados trances del juramento (así la denegación del delito no será un perjurio) y del duelo judicial contra el acusador, el malvado Hardré. Entre los motivos literarios del episodio, hallamos una semejanza gemelar, el intercambio de vestidos y el ofrecimiento de su propia vida por la del amigo. ${ }^{47}$ Por su raigambre hagiográfica y religiosa, el argumento encierra connotaciones crísticas, tan patentes que huelga explicitarlas, extremo que se ve corroborado, como ya fue señalado, por su frecuente inserción en ejemplarios homiléticos.

La intertextualidad de la obra luliana con respecto al Ami et Amile, interpretado en clave teológica, aparece en la onomástica general, amic $i$ amat, y, con mas estrecho paralelismo, en los poemas 30/29 y 254/261, que se basan en el motivo literario del trueque de vestidos. ${ }^{48}$ Amat ofrece su vida por la salvación de amich, revistiendo su carne mortal (la gonella de son amich) y sufriendo en lugar del amigo:

45 En el caso de Llull, tenemos la impresión, por supuesto imposible de verificar, de que las gracias iniciales de conversión predominan sobre las gracias terminales de unión. Para algunos teorizadores de la espiritualidad, como nuestro fray Luis de León, puede darse una vivencia mística, como el «ilapso interior», desde la primera etapa purgativa de conversión: Luis de León, In Canticuñ canticorum triplex explanatio, cap. 1, citado por José L. Hervás, Entrañados en Cristo. La mística teológica de fray Luis de León, Pamplona, Eunate, 1996, p. 40.

46 Puede leerse, por ejemplo, dicho relato en el Speculum historiale de Vincent de Beauvais, el Alphabetum narrationum, la Scala coeli de Jean Gobi junior, y el Recull d'exemplis.

47 Ami et Amile, $\$$ 59-60 y 161, J. Blanchard y M. Quereuil (trad.), París, Honoré Champion, 1985, p. 34-35, 68.

48 Para la gemelidad del amigo y el amado: $\$ \S 76 / 76,78 / 78,183 / 189,208 / 214,264 / 271,346 / 354$; entre las personas de la trinidad divina $\S 253 / 260$. 
[30/29]. Desobehí l'amich son amat, e plorà l'amich. E l'amat vench murir en la gonella de son amich per ço que l'amich recobràs ço que havia perdut. E donà-li mayor do que cell que perdut havia.

Al parecido gemelar, el Ami et Amile añade la idea de una perfecta reciprocidad (amatio et redamatio) en la amistad caballeresca. Mientras Ami afronta el proceso y el duelo, el «contumaz» Amile se sustituye a él — con ejemplar y heroica castidad - en el lecho conyugal; y más tarde el mismo Amile, para corresponder al gesto oblativo de Ami en el duelo, sacrificará a sus propios hijos para curar con su sangre la lepra de su amigo gemelar, en un episodio que encierra, sin duda, la más transparente alegoría de la redención. Dicha reciprocidad, Ramon Llull la expresa en Laa 254/261, cuando se describe el mirabile commercium de la encarnación (Dios se hace hombre, para que el hombre se «endiose»), valiéndose para ello de motivos literarios muy semejantes a los del Amis et Amile, como son la semejanza gemelar, el trueque de vestidos y la reciprocidad en el sacrificio pues a la Pasión del amado corresponde el anhelo martirial del amigo (vermells vestiments):

[254/261]. Vestî's l'amat del drap on era vestit son amic, per ço que fos son companyó en glòria eternalment.

E per açò l'amich desirà tots jorns vermells vestiments, per ço que.l drap sia mills semblant als vestiments de son amat.

El interés de dicha referencia trasciende, a nuestro entender, la mera identificación de fuentes, pues, de verificarse, tendería a asentar que la pareja central del opúsculo, amic $i$ amat (tan extranjera a los códigos coetáneos vigentes en la poética cortés como en la mística nupcial), no tendría sin embargo un carácter totalmente atípico dentro de las formas culturales romances, y, por consiguiente, ya no se impondría el elucidarla, echando mano a la poesía árabe con su ambivalencia sexual amado/a para designar el correlato del amante.

Entre los veneros que confluyen en el Laa, nada hay de novedoso en rastrear influencias trovadorescas, tarea que ya fue intentada, con algún acierto, por Manuel de Montoliu, si bien señala sobre todo paralelismos temáticos, lugares comunes, difícilmente atribuibles a un autor. ${ }^{49}$ Por nuestra parte, creemos que una intertextualidad más precisa puede establecerse entre Ramon Llull y Cerverí de Girona (+ post 1285), a propósito del poema 329/337, si bien dicha muestra no entronca con la canço lírica sino más bien con el sirventès moral.

[329/337] Odorà l'amich flors, e remembrà pudors en rich avar e en luxuriós e en desconexent ergullós [...].

Ramon Llull retoma aquí, en una versión troncada, el tópico de los cuatro vicios contra naturam que ya fuera desarrollado por Pierre de Maubeuge, a partir de un dicho sapiencial del Eclesiástico: ${ }^{50}$ ser pobre pero vanidoso, anciano pero lujurioso, rico pero codicioso, joven pero

49 El paralelo más convincente nos parece ser el que se establece entre Laa $18 / 17$ y una tençó de Guerau de Salignac y Peironet (debate entre los ojos y ei corazón): Montoliu, art. cit., pp. 383 y 390 .

50 El Eclesiástico (XXV, 3-4) bosqueja, en efecto, tres tipos humanos, que juzga abominables: «Tres species odivit anima mea, et aggravor valde animas illorum: pauperem superbum, divitem mendacem, senem fatuum et insensatum». 
indolente. $^{51}$ Ciertamente la exacta correspondencia, con el sirventès de Cerverí, ${ }^{52}$ se limita al «rich avar»y, en menor medida, al «desconexent ergullós» (desagradecido orgulloso), que remite indirectamente a una situación de indigencia material o moral. Más complejo resulta el caso del anciano lujurioso, pues sólo se lee «vell luxuriós» en una versión tardía del $L a a$, la edición valenciana de Joan Bonllavi en 1521. Si Ramon Llull adopta, en la refundición del tema, una estílistica de la abreviatio, en dependencia del género adoptado, encontramos, al contrario, en Cerverí de Girona, una considerable amplificatio del tema, lo que se traduce por un catálogo más amplio de dichos vicios contra naturam, con ribetes de sátira social, cuyo blanco es la inversión de valores en un mundo trastocado, donde los siervos mandan a los señores, y el vicio a la honradez. ${ }^{53}$

Antes de cerrar este apartado, nos limitaremos a reseñar otras afinidades entre Cerverí y el Laa $(\$ \$ 26 / 25,328 / 336)$, que pueden explicarse por la adopcion del mismo subgénero, el alba «a lo divino» y el testament, dos tópicos bastante difundidos en la poesía trobadoresca. ${ }^{54}$

\section{CONCLUSIÓN}

Al final de nuestro viaje intertextual por caminos y vericuetos del Laa, y para reducir nuestro intento a sus justas proporciones, enunciaremos una evidencia que, por palmaria, se nos podría quedar en el tintero. No puede sino llamar la atención la facultad de «interiorización» de Ramon Llull, su apropriación de temas y motivos, como sillares de su propria construcción, lo que se traduce, en el plano de la estrategia textual, por la ausencia total de citas, esas ringleras de auctoritates, tanto especulativas como espirituales, tan acordes con el talante compilador y tradicional de la cultura medieval.

Entre los fracasos de nuestra pesquisa, y como tarea que dejamos para otros investigadores, mencionaremos la identificación de las fuentes, si las hubiera, para una doctrina antropológica del primer Ramon Llull, a saber su concepción de los cinco sentidos espirituales (subtilitat, cogitació, apercibiment, consciència, coratge-frevor), donde parecen entrelazarse la tradición médica —sobre todo aviceniana - de los sentidos internos ${ }^{55}$ y la tradición mística de los sentidos espirituales que

51 Pierre de Maubeuge, dans K. Busby (ed.), Pluteus 3, 1985, pp. 37-56.

52 Se mencionan al «paubr" ergoyllos» (§ $1 \mathrm{f})$, al «veyls luxurios» ( $\$ 2 f)$ y al «ric envejos» ( $\$ 3 f):$ Cerverí de Girona, «Princep enic e bisbe negligent», n. ${ }^{\circ} 82$, Obras completas del trobador [...], M. de Riquer (ed.), Barcelona, 1947, pp. 230232. Para la posteridad del tema en el ámbito catalán: Ausias March, «Qui ne per si [...]», n. ${ }^{\circ} 104, \S 29$, dans Poesies, $\mathrm{P}$. Bohigas (ed.), Barcelona, Barcino, 1952-1959, IV, p. 110 ; Joanot Martorell y Marti Joan de Galba, Tirant lo Blanc, cap. 192, M. de Riquer (ed.), Barcelona, ed. 62, 19927, vol. 1, p. 421.

53 En su amplificación de la sátira, el trobador parece depender de «los doce abusos del claustro», desarrollados por: Hugo de Fouilloy, en De claustro animex, L.2, cap. 11-17, PL 176, c. 1061-1070; por ejemplo «bisbe negligent» (\$ 1a), «jove antich e desobedien» ( $\$ 2 \mathrm{a})$, «clerc malfazen e pauc adoctrinat» ( $\$ 2 \mathrm{~b})$, «fols religios» ( $\$ 5 \mathrm{f}$ ).

54 Cerverí de Girona, o.c., n ${ }^{\circ} 20$ y 119, p. 51-53, 373-378. En términos de intertextualidad, se encuentran asimismo parecidos muy llamativos entre el Sermó de Cerverí y otra obra luliana, el Llibre de contemplació, con la alegorización de Cristo en tres oficios para madrugadores, o sea el mercader, el peregrino y el campesino: Cerverí, o.c., n.$^{\circ} 118$, $\S \S, 2-6$, p. 364-369 ; cfr. Ramon Llull, Libre de contemplació, cap. 113, 116, 121, OE II, p. 341-366.

55 Para un estudio de los sentidos externos e internos en las letras castellanas: J. Homer Herriott, «The Ten Senses in the Siete Partidas», Hispanic Review, 20 (1952), pp. 269-281. 
duplican la sensitividad física del hombre ${ }^{56}$ Esa sensitividad interna del hombre ofrece a Llull un instrumental para nombrar y clasificar experiencias que corresponden a la esfera de la interioridad $\mathrm{y}$, si bien tal o cual equivalencia - sobretodo cogitatio, subtilitas ou ingenium, fervor- se puede hallar en otros autores medievales, no tenemos conocimiento de ningún otro sistema que se asemeje a su versión de los cinco sentidos internos. Si lamentamos el fracaso de nuestra pesquisa, es porque, al tratarse de una clasificación bastante atípica, hubiera podido servirnos de hilo para desenmadejar, en parte, el enmarañado ovillo de las fuentes lulianas.

También queda por realizar un análisis genérico y estilístico del Laa, tarea que no hemos deseado emprender, en este artículo, a causa de los intereses filosóficos que predominan, lógicamente, en la revista que me brinda la hospitalidad de estas páginas. Por haberlo argumentado en otros trabajos, no volveré a romper lanzas a favor de mi convicción de que nos hallamos - pese a la ausencia de métrica regular y de rima final- frente a un canto poético, tanto o más que frente a una colección de exempla. ${ }^{57} \mathrm{~A}$ este respecto, viene produciéndose un sesgo crítico, que tiende a privilegiar el componente didáctico de la obra, sin duda por reacción pendular frente a los excesos de una crítica lastrada por un vago subjetivismo romántico. Por nuestra parte, no podemos sino simpatizar con dicha reacción, aunque sólo fuera por haber intentado contribuir, en trabajos anteriores, a esclarecer el entramado filosófico del texto. Si mantenemos, a pesar de todo, cierta reticencia hacia el rótulo «didáctico» ello obedece a dos motivos: en primer lugar, su empleo «exclusivista», cuando equivale a denegar el estatuto poético del texto; en segundo lugar, lo impreciso de la noción de «didactismo» —un auténtico cajón de sastre metodológico- que conviene, por de pronto, deslindar y, luego, desglosar en subgéneros.

En su sentido actual, el didactismo enuncia una relación de maestro a maestro, pero concedemos que se pueda ampliar sin excesivos inconvenientes a una relación de maestro a discípulo. Aun en ese caso, no creemos que dicha noción sea pertinente para definir el Laa, donde no vemos traslucirse, ni por asomo, una relación de tipo magisterial. Por otra parte, el rótulo «didáctico» debiera reservarse a obras que privilegian la transmisión de contenidos cognitivos, por ejemplo un catecismo, sin confundirlas, aunque no siempre resulta tarea fácil, con géneros morales 0 «tropológicos» - sapienciales, si se prefiere-, en los que predomina la transmisión de comportamientos pragmáticos. En este sentido, un sermón no será didáctico, porque un parroquiano podrá escucharlo, e incluso de buena gana, sin que, necesariamente, se amplie por ello el área de sus conocimientos.

En resumidas cuentas, y según los dos criterios aducidos - relación magisterial y dominante cognitiva-, el Laa no encaja en la casilla del didactismo, y sólo a duras penas, como veremos, en el género tropológico-moral. En efecto, la problemática del amor contemplativo predomina a todas luces sobre los contenidos de tipo pragmático, más corrientes en el exemplum, como son la censura de vicios y la exhortación de virtudes, en torno al estadio ascético de la existencia cristiana ( $\$$ 58/57). Para decirlo en términos de exégesis medieval, el sensus anagógico, tomado en su acepción amplia, coexiste, pero en posición dominante, con el sensus moral o tropológico.

56 Vid: Mariette Canévet, «Sens spirituel», en Dictionnaire de spiritualité, Paris, Beauchesne, 1932-1995, vol. 14, c. 598-617.

57 Serverat, «Chanter à deux voix. Poésie et altérité chez Ramon Llull», AION, Naples, 1993, pp. 608-619; vid. asimismo Montoliu, art. cit., pp. 376-377. 
Tras este primer deslinde, se puede proceder a un desglose o tipología entre varios subgéneros mal llamados didácticos, de los que figuran, en el Laa, por lo menos tres tipos fundamentales: el exemplum y el proverbium ( $\$ 33 / 32$ ), ${ }^{58}$ junto con lo que proponemos llamar meditatio, oratio ou soliloquium ( $\$ \$ 289 / 296-293 / 300$ ). Al ser bastantes marginales el proverbium y la meditatio, en nuestro texto de referencia, conviene centrarse en el exemplum, cuyos principales rasgos en el Laa serían el predominio del diálogo sobre la narración, así como la frecuente ausencia de secuencia hermeneútica explícita, en términos castizos, la moraleja. ${ }^{59}$ La elipsis de la moralidad está acorde con el carácter, más bien místico-espiritual que ascético-moralizador, de la obra. Esto dicho, el silenciar la secuencia hermeneútica, como en la literatura sapiencial de origen oriental (y en el mismo Fèlix de Ramon Llull), puede constituir asimismo un procedimiento didáctico-moral, y que obedece a una lógica de aprendizaje autónomo, de ahí que el versículo del Laa, aun falto de moraleja, pueda encasillarse en el género del exemplum. ${ }^{60}$

El exemplum, a su vez, debería subdividirse en una tipología, que a lo menos comprendiera: los exempla propiamente dichos, con carácter narrativo; las similitudines más bien descriptivas ( $\$ \S$ $42 / 41,45 / 44)$; las formas mixtas, o exemplum-similitudo $(\$ 23 / 22){ }^{61} \mathrm{y}$, por último, otros tipos menos estudiados como son el caso y el enigma. ${ }^{62}$ El más espinoso problema taxonómico estriba, a nuestro entender, en la clasificación de los numerosos exempla interrogativos, identificables a menudo por el enunciado qüestió fo, y que pueden tener cabida, teóricamente, por lo menos en tres

58 Al no tener carácter namativo, el proverbium se caracteriza, entre otros muchos criterios, por su enunciación al presente (pero también puede ser el caso para la similitudo) y por la ausencia de actantes (amic y amat son enunciados pero no personajes de una acción). Como una contribución minúscula a la fijación del texto, expresamos nuestra duda, en $\S 30$, con respecto al presente «enamora» en vez del pretérito «enamorà», modificacion temporal que acarrea un cambio genérico d'exemplum a proverbium.

59 Predominancia de la mimesis dialogal y carácter implícito del nivel hermeneútico, son afirmados, de manera metatextual, por el autor:: Ramon Llull, Libre d'Evast e d'Aloma e de Blanquerna, cap. 99, OE I, p. 260-a.

60 Encontramos, sin embargo, una explicitación, de orden interpretativo-cognitivo, en algunos casos de similitudo ( $\$ 42 / 41)$ o d'exemplum-similitudo ( $\$ 23 / 22)$, sin duda por el carácter metafórico de estos subgéneros, que reclaman un desciframiento, en mayor medida que los exempla sinecdóquicos. Dicho de otro modo, la similitudo, por su estatuto metafórico, parece exigir una secuencia interpretativa de orden cognitivo (allegoria), lo cual no sucede con el exemplum narrativo, al que suele bastar, por su estatuto sinecdóquico, una secuencia pragmática (tropologia o anagogia), cuya eventual elisión, como en el Laa, plantea, además, menores problemas para la cabal comprensión del texto. Por dicho motivo, no compartimos la teoría de S. Suleiman, según la cual se dan conjuntamente, en toda «moraleja», dos niveles -interpretativo y pragmático-, ya que, a nuestro modesto entender, la presencia de un sólo nivel es suficiente para constituir un exemplum (aunque no son frecuentes, puede haber exempla puramente cognitivos, y muy numerosos son los exclusivamente pragmáticos): cfr. María Jesús Lacarra, «El libro de los gatos: hacia una tipología del enxiemplo», en Y.-R. Fonqueme y A. Egido (coord.), Formas breves del relato, Univ. de Zaragoza, 1986, p. 30. Para el doble procedimiento de transducción metafórica o de inducción sinecdóquica: Cl. Brémond, J. Le Goff, J.-C. Schmitt, L' «exemplum»., dans Typologie des sources du Moyen Age occidental 40, Tournai, Brepols, (1982), pp. 115-119.

61 Entendemos por exemplum-similitudo, lo que M. J. Lacarra denomina allegoria, y englobamos en similitudo su categoría de descriptio: Lacarra, art. cit., p. 34.

62 Para las nociones de exemplum-caso y de exemplum-enigma: Brémond, Le Goff, Schmitt, o.c., p. 46 y 127 . El enigma no remite al acertijo, sino a una ruptura de la causalidad, que se debe reconstruir mediante una pesquisa, valga el anacronismo, de tipo policíaco. En el «caso», que no tiene necesariamente forma interrogativa, se contrasta una norma general (religiosa, jurídica, amorosa, etc.) con una situación individual, intentando salvaguardar a la vez la validez de la norma y lo insoslayable de las circunstancias. Para una ilustración que nos parece paradigmática: Don Juan Manuel, $E l$ Conde Lucanor, XXVII[b], J.M. Blecua (ed.), Madrid, Castalia, 1969, p. 156-160. 
subgéneros diferentes: el caso, el acertijo y el debate, este último tan frecuente en el opúsculo, y al que proponemos llamar exemplum-qucestio ( $\$ \$ 18 / 17,19 / 18) .{ }^{63}$

Al diseñar, a grandes trazos, lo que pudiera ser un programa investigador, deseamos, por de pronto, demostrar que la adscripción del texto al didactismo es una solución que, lejos de zanjar el problema, plantea nuevos y apasionantes interrogantes. Pero tal vez no sea esto lo más importante, sino el tomar conciencia del excepcional polimorfismo que caracteriza el versículo luliano en el Laa: «per tal que de diversses maneres e de moltes componés lo Libre d'amich e amat» (pròlech). Por consiguiente, si se quiere avanzar en la cuestión pendiente de la dispositio de la obra —el orden subyacente a la compilación-, cabría adoptar una óptica más estilística y menos doctrinal de la seguida hasta ahora. Una de las claves de su composición quizás no radique tanto en sus contenidos como en su estilística, o sea una estrategia textual que consiste, ora en alternar formas heterogéneas del discurso, ora en hilvanarlas dentro de series homogéneas. A menos de andar totalmente descarriado - que con todo es menester contar-, nos parece que la elaboración de una cartografía de los subgéneros, presentes en el Laa, podría contribuir a elucidar el enigma de su estructura, solución tal vez decepcionante, en su formalismo escueto, para los aficionados al arcano, que nunca faltaron en la variopinta grey de los lulistas.

Puede parecer extraño que nuestro estudio sobre las fuentes, la matèria doctrinal de la obra, tenga como colofón una tan escrupulosa atención por su manera estilística, según la dicotomía, atenuada por la paronomasia, que Llull enuncia en su exordio. ${ }^{64} \mathrm{Tal}$ vez sea lo que se espera de un investigador en literatura, cuando se le abren las columnas de una publicación filosófica. Razón de más para acabar con una nota provocadora que, trastocando el símil convenido del discurso sapiencial, sitúe la falacia de un texto en la fruta o meollo, y su verdad, al contrario, en las cascas. Más exacto sería decir que el escritor señero, si no tiene por qué morar más allá del bien y del mal, nunca deja de asentarse en la unidad de la cumbre, más allá de la separación entre fondo y forma, idea y palabra, matèria y manera.

\author{
Vincent Serverat \\ Université Stendhal-Grenoble III \\ BP 25 \\ 38040 Grenoble codex 9
}

63 Se trataría de acertijos, si la respuesta fuese única, pero de quctestiones si el interrogante puede dar lugar -y es el supuesto más habitual- a un intercambio de varios argumentos en pro y en contra, sean explícitos o implícitos, según el método universitario del sic et non. En el caso, al contrario, no se oponen dos verdades generales, sino una verdad general y una situación particular.

64 Ramon Liull, Libre d'Evast e [...] de Blanquerna, cap. 99, OE I, p. 260-a. 